\title{
A research on the use of metaphor design in promoting brand identity
}

\begin{abstract}
Every new brand which competes and increases its market share needs some tools and methods to be applied to its products. The objective of this research is to investigate the use of metaphor as a tool for peak shift effect and its impact on memory, which can be effective in promoting brand identity from a customer perspective. In this respect, this research uses a combination of memory test and comparison of two objects method. Therefore, the research method was according to environment specifications. The results indicated that the products having metaphor in comparison to products with no metaphor has an effective role in peak shift and image persistence and its name in user's mind. In conclusion, the brand identity can be promoted in a variety of ways, among which the design of metaphor, which is related to product design and graphic design, is one of these ways.
\end{abstract}

\section{KEY WORDS}

metaphor design, peak shift, branding

\author{
Bahram Ipaki \\ Yazdan Movahedi \\ Parisa Jourabchi \\ Amirkhizi \\ Tabriz Islamic Art University, \\ Faculty of Islamic Design, \\ Tabriz, Iran \\ Corresponding author: \\ Bahram Ipaki \\ e-mail: \\ ipakdesign@gmail.com
}

First recieved: 04.08.2018

Accepted: 01.10.2018.

\section{Introduction}

Companies need a corporate identity to have a good relationship with each other, so they seek a way to create a unique and durable sense to impress their customers (Wheeler, 2009). According to American Marketing Association, brand is a name, sign, symbol, design, or a combination of all of these (Keller, 2013). Brand use some elements as graphics, color, texture, voice, shape, symmetry, rhythm, and other gestalt and cognitive elements to be identified (Kevin Budelmann, 2010). A mixture of all these elements shapes the brand identity. From cognitive outlook, brand have a tangible fascination so can be touched, held, watched and even can be moved (Wheeler, 2009). Some product-oriented brands require good quality and reasonable price according to product's usage time, so that they can communicate with their customer, user, or consumer (Heine, 2012). A corporation, company, or manufacturer should imply its principles in their products to engrave its brand identity on customer's mind. A deep understanding of customer or user through signs and functions of brand which is now being attended by neuroscience, is one of these principles (Leslie de Chernatony, 2011; Maiocchi, 2015). Perceptual memory perceives sense respectively through visual, auditory, physical communication, and other communications (Robier, 2016). Figure 1 shows the amount of accuracy of information perceived by perceptual memory which is presented by the communication type. 


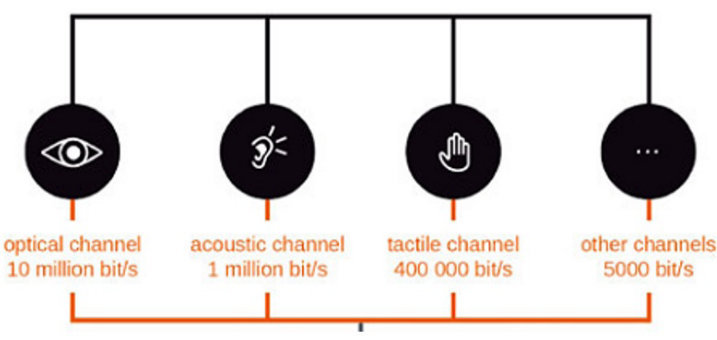

» Figure 1: Accuracy of cognitive memory in bit (Robier, 2016)

There are three kinds of memory in the human brain which include sensory memory, short-term memory, and long-term memory (Robier, 2016). All messages are first sent to the sensory memory by neurotransmitters which are called dopamine. Then the messages are sent to short-term memory in the case of dopamine increase that is dependent on the type and intensity of communication, and then to the long-term memory (Robier, 2016; René Riedl, 2016). As shown in Figure 1, the most transmission of the messages through the dopamine increase is by visual communication. Sudden increases in dopamine are called peak or peak shifts (S. K. Lynn, 2010). Peak shift is a behavioral attribute that is triggered by a stimulus like sight, auditory, touch, and so on (Maiocchi, 2015). In design, peak shift is also a part of Ramachandran's 9 principles which provides the availability of increase of neurotransmitters (mainly dopamine) for emotions mainly through magnetic resonance imaging (Ramachandran, 1999; Maiocchi, 2015). There are usually various sensory features that can be found in the products and the user feels them in the course of use. These features actually cause the peak shifts in user. The metaphor is another tool to make peak shifts (Maiocchi, 2015). Metaphor design is the use of form, Interaction, sound, movement, material, smell and taste, name and graphics (CILA, 2013). Metaphor design is made up of a source and a purpose (Bae, 2012). For instance, our purpose is to design a fire extinguisher. Now we can select a source and combine these two to design the final product; and this creates a special "code" and "meaning" in the person's mind (Maiocchi, 2015; Cila, 2013).

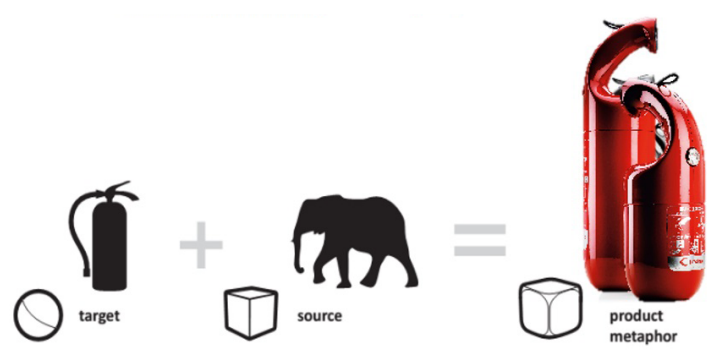

» Figure 2: The metaphor design process

[target + source $=$ product metaphor] $($ Cila, 2013)

Here the source is the elephant's features like body form, the physical and psychological functions of the elephant such as motion, sound and etc. which combines with the specific purpose (CILA, 2013). This can apply peak shift. However, we still do not know if the intensity of these shifts in the products with metaphorical features and bare-metaphor products is the same or not. This question is the subject of this research. One of the advantages of applying a metaphor to the product is to establish a sensory relationship with a customer or user, as a specific code passes to the user's mind and this code engages a person's long-term memory in his/her sensory memory (Maiocchi, 2015) (Robier, 2016) (CILA, 2013). The amount of brand's sustainability in memory reflects the fact that metaphor has a special ability to transmit codes to brain which makes an identity to remain in long-term memory or mind. The main topic is this code or sign of product which is interpreted by user, and this may show the distinction in his/her mind with products with no metaphor. The main problem is that new brands and start-ups need some instructions and processes to promote their corporation identity. Now this question arises that whether products using metaphor make higher peak shifts rather than products have no metaphor or not. And the last question is, how shifts peak promotes the brand identity.

\section{Method}

Since the purpose of the research was to compare two different types of brand, in this research, we had come to combine several different standard methods. The statistical population was selected through the "non-random sampling" method so that we could generalize the population. In this regard, talented students of Allameh Helli High School in Hamadan Province were chosen. Choosing talented students was done because of their level of memory health and high intelligence that can well cover the research objectives. First, 5 products having metaphor features with a letter for each of them were presented to students in the form of a slideshow. Each image was shown for just 0.8 seconds and after the presentation, the name of the products was asked students in a questionnaire. Second, another group of 5 products without metaphor, were again presented to same students in the form of a slideshow, each slide for 0.8 seconds and again asking some questions via questionnaire. Confounding factors like the level of intelligence, moderated in two steps to not to lead up any comparison. That is, one's memory was compared with two different kinds of its own. The age factor also was selected between 15 to 18 years of old regardless of gender; and this was due to level of education and also because here gender do not influence the results. Since talented students need to be admitted to talented education centers by passing special tests, we considered all the students of a high level of intelligence. To moderate the name of the brands, some fake one-letter names were selected obsessively in two groups, one group for products having metaphor and another group 
for products without metaphor to lessen the impact of name and to bold the image in the test. To avoid the impact of images memorizing loads that might make the first images be forgotten, two first images unlisted and presented without names. So these two products having no metaphor and neither name is shown in Figure 3.
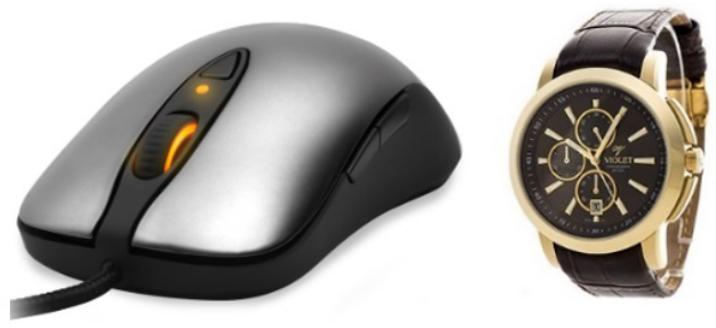

» Figure 3: 2 first products with no metaphor and neither name at the begging of the slideshow

\section{Test method}

First, the images were shown to examiners without prior notice, in SIBOL and CHAPK letters order, and after observing the image phase, students should mention the brand names or say nothing if could not, and then the next question was asked. The number of given replies, true, false, and the blank was calculated by Excel software. The respondents should arrange the names of products in an open-ended questionnaire, after observing the slideshow. Responses should be in the order of SIBOL and CHAPK. If the test was done randomly, it would be very difficult to measure the results. 2 products of Figure 3 are used to avoid bias in the test.



$\mathrm{S}$

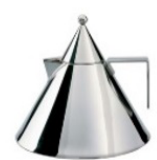

I

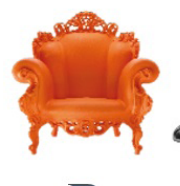

B

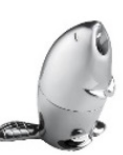

0

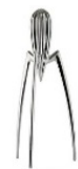

$\mathbf{L}$
» Figure 4: Products having metaphor with their brand name. Adapted from study

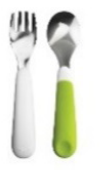

C

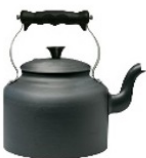

H

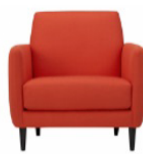

A

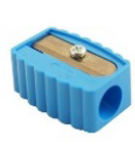

$\mathbf{P}$

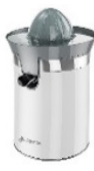

K
» Figure 5: Products have no metaphor with their brand name. Adapted from study

\section{Results}

The purpose of this research was to prove metaphor design as a useful tool for promoting brand identity. In this respect, the slideshow test was conducted through Focusky presentation software and the answering to the open-ended questionnaire were held in the auditorium of Allameh Helli School. All responses were analyzed using Excel software. 79.8\% of SIBOL responses for products having metaphor were correct, while only $47.65 \%$ of CHAPK response for simple products with no metaphor was correct. Blank, wrong, and redundant answers of both questionnaires were $72.55 \%$ of total $200 \%$. The first phase of the test was to evaluate the sensory and short-term memory of students. The second phase was conducted after two hours to assess the long-term memory. This time, results were somehow different and almost $63 \%$ of SIBOL responses were correct, while almost $32 \%$ of answers for CHAPK were correct. This indicates that the time difference leads to memory decrease at the short-term memory.

In products having metaphor, product $\underline{\mathbf{S}}$ had the most error. It is maybe because it is too new to respondents. It is clear that there is some complexity in this research. The product I also had the highest degree of accuracy in the test. This indicates that the simplicity of the form also affects the mind because the product I is a combination of triangles so has a more familiar structure than other products having metaphor. Here, a code is made that has an effect on the mind; a code based on the recognition of an earlier image or structure and it has a positive impact on memory learning. In the following, product $\underline{\mathbf{B}}$ does not have a high score on the correctness of the responses because of the simplicity of the image. Because Alessandro Mendini has used polyethylene material and in some cases ceramic compounds in the product's design. Using these two materials in a couch design looks strange. So the audience will be encouraged to experience it. Although $\underline{\mathbf{B}}$ has fewer points in the correctness of the responses, it seems that it makes a higher impact on peak shifts in the process of use. Perhaps Mendini, here, wanted to create a special experience for the user. In the case of CHAPK products, the responses were also very variable and varied. Perhaps if the letters were in accordance with the structure of the products, the results were different. For example, if the $\underline{\mathbf{I}}$ kettle was renamed to $\underline{\mathbf{A}}$, and then the test was done, the results might have been better. Because $A$ has a triangular form that is very similar to the Kettle $\underline{\mathbf{I}}$.

\section{Conclusion}

To avoid any bias, we just used English letters. Additionally, students were more familiar with English letters. If the words were used instead of letters, then the structure, syllable, and the voice of the word would affect 
the answers. On the other hand, the basis of the test was product images. As the level of memory was of importance, the examiners were selected from talented students. The main purpose was a comparison of two factors and eventually the results showed that SIBOLbased image, products having the metaphor, had more impact on memory. High peak shifts in the brain are often measurable by devices such as Electroencephalography; however, according to formers researches, seeing or other senses can also effect the peak shifts that can be measured by memory testing methods. This research found that products having a metaphor have this ability to stick to memory longer. Finally, it is concluded that designs using metaphor leads to more peak shifts than ones lack this feature and also affect the memory more. A fall of approximately $15 \%$ in both test modes is quite evident but this problem can be solved by repeating the test by showing the product with its brand or identity. The main issue is that the effect of the designs of using metaphor is quite clear in comparison to the simple ones. Specific shapes also engage the brain. Metaphor design in the product is quite odd and strange for the observer. As a result, the brand identity can be more well-known and bear in mind in many different ways; and among them, metaphor design which is in the relationship with product design science and graphic design is one of these ways.

\section{Recommendations}

1. Start-ups and new brands can employ metaphor design process to promote their brand identity, to be recognized and win more market share.

2. Using metaphor in design is one of the fastest and most effective ways for corporations to introduce a brand identity to its users or customers.

3. Because of the high cost and complexity of metaphor design, it is better to use it in a cross-sectional form or when radical reforms are made to the company's strategies.

4. Metaphor design with the help of interactive elements of five senses can be implemented in the form of product, packaging, goods or services.

5. It is recommended to the next researchers to use this study for their own product or service since metaphor as a tool is highly dependent on the type of product or service

\section{References}

Bae, Y. (2012) Design through metaphor. MSC thesis. Aalto University School of Arts, Design and Architecture, Aalto.

Cila, N. (2013) Metaphors we design by: The use of metaphors in product design. Phd thesis. Middle East Technical University geboren te Bursa, Bursa. Available from: doi: 10.4233/ uuid:b7484b0f-9596-4856-ae9d-97c696f9de79.

Heine, K. (2012) The Concept of Luxury Brands. 2nd ed. Technische Universität, Berlin.

Keller, K. L. (2013) Strategic Brand Management Building, Measuring, and Managing Brand Equity. Tuck School of Business Dartmouth College, London.

Budelmann, K., Yang, K., \& Wozniak, C. (2010) Brand Identity Essentials 100 Principles for Designing Logos and Building Brands. Rockport Publishers, Rockport.

Chernatony, L., McDonald, M., \& Wallace, E. (2011) Creating Powerful Brands. 4th ed. Elsevier, Amsterdam.

Maiocchi, M. (2015) The Neuroscientific Basis of Successful Design How Emotions and Perceptions Matter. Springer, New York.

Ramachandran, W. H. (1999) The Science of Art A Neurological Theory of Aesthetic Experience. Journal of Consciousness Studies. 6 (6-7), 15-51.

Riedl, R., \& Léger, P-M. (2016) Fundamentals of Neurols Information Systems and the Brain. Springer, Berlin.

Robier, J. (2016) UX Redefined Winning and Keeping Customers with Enhanced Usability and User Experience. Springer, New York.

Lynn, S. K. (2010) Decision-Making and Learning: The Peak Shift Behavioral Response. 1. 470-475. Encyclopedia of Animal Behavior, Oxford. Available from: doi: 10.1016/B978-0-08-045337-8.00146-7.

Wheeler, A. (2009) Designing Brand Identity: An essential guide for the whole branding team. Wiley, New Jersey.

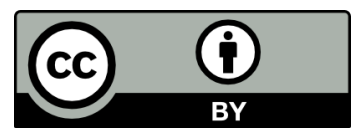

(C) 2018 Authors. Published by the University of Novi Sad, Faculty of Technical Sciences, Department of Graphic Engineering and Design. This article is an open access article distributed under the terms and conditions of the Creative Commons Attribution license 3.0 Serbia (http://creativecommons.org/licenses/by/3.0/rs/). 